\title{
PHOTOGRAMMETRY AS A TOOL FOR LIVING ARCHITECTURE
}

\author{
W. Middleton ${ }^{1 *}$, Q. Shu ${ }^{1}$, F. Ludwig ${ }^{1}$ \\ ${ }^{1}$ Green Technologies in Landscape Architecture, Technical University of Munich (TUM), Arcisstrasse 21, 80333 Munich, Germany \\ - (wilf.middleton, qiguan.shu, ferdinand.ludwig)@tum.de
}

Commission II

\begin{abstract}
:
Living Root Bridges (LRBs), grown by rural Khasi and Jaintia communities in Meghalaya (India), are the best known example of functional living architecture. Over 70 bridges, as well as ladders, pathways and platforms have been grown from a single species (Ficus elastica), using a collection of construction methods in regionally specific environmental conditions. In general, living architecture exhibits geometric complexity for which documentation and representation tools are yet to be established. Photogrammetric surveys provide data-rich point clouds which could be useful for analysis and design specific to living architecture. This study provides the first photogrammetric surveys of LRBs. Useful point clouds were produced for several bridges, as well as joint details. The method is found to have a range of benefits: providing detailed views, showing environmental conditions, and allowing for time analyses. The wider application of photogrammetry to living architecture is discussed, particularly with regards to Baubotanik structures and the improved documentation and representation of LRBs as a unique architectural typology. The need for developing a tool for topological model extraction, and possible methods therein is discussed.
\end{abstract}

KEY WORDS: photogrammetry, living architecture, living root bridges, Baubotanik

\section{INTRODUCTION}

\subsection{Living Root Bridges}

Living Root Bridges (in Khasi, Jingkieng Jri), grown by rural Khasi and Jaintia communities in Meghalaya (India), are the best known example of a functional living architecture (Ludwig et al., 2019). Rural village communities have used a single species, the Indian Rubber Fig, Ficus elastica, to grow more than 70 Living Root Bridges (LRBs), as well as ladders, pathways, and platforms. A bridge is begun by training aerial roots, common to the strangler figs (Jim, 2014) over a scaffold (usually bamboo, readily available in the surrounding forest) to cross a river or canyon. The roots are allowed to implant in the opposite bank or graft onto another tree of the same species. They then thicken and produce daughter roots, which are woven together into a stable bridge, as discussed in more detail by (Ludwig et al., 2019) and (Shankar, 2015). (Shankar, 2015) provides a basic description of the bridges, their construction techniques, and compares their sustainability with steel suspension bridges in the region. (Ludwig et al., 2019) discusses bridge distribution, length, history and construction methods and describes two structurally interesting components of LRBs: thick, structurally important roots and inosculated joints. That study highlights structural and architectural trends and provides methods useful for comparative studies between LRBs, and between their constituent parts - see Figures 3,4 and Figures 2,7 respectively in (Ludwig et al., 2019).

Structurally important roots appear to make up much of the mass of many LRB decks, while they are bound together into a network by inosculated joints. Inosculations are anastomoses, formed by sustained contact between stem surfaces allowing intergrowth (Millner, 1932). (Zimmermann et al., 1968) describes the 3-phase growth of Ficus benjamina aerial roots: primary growth of a thin flexible root, followed by tension wood thickening growth once the root has anchored (in soil or by inosculation), then additional thickening to support compressive loads. (Abasolo et al., 2009) describes similar processes in $F$. elastica, establishing mechanical properties of aerial roots. When a young root is tied into a knot (Figure 1c), then planted in the ground, the tensionwood growth provides pressure that sustains surface contact,
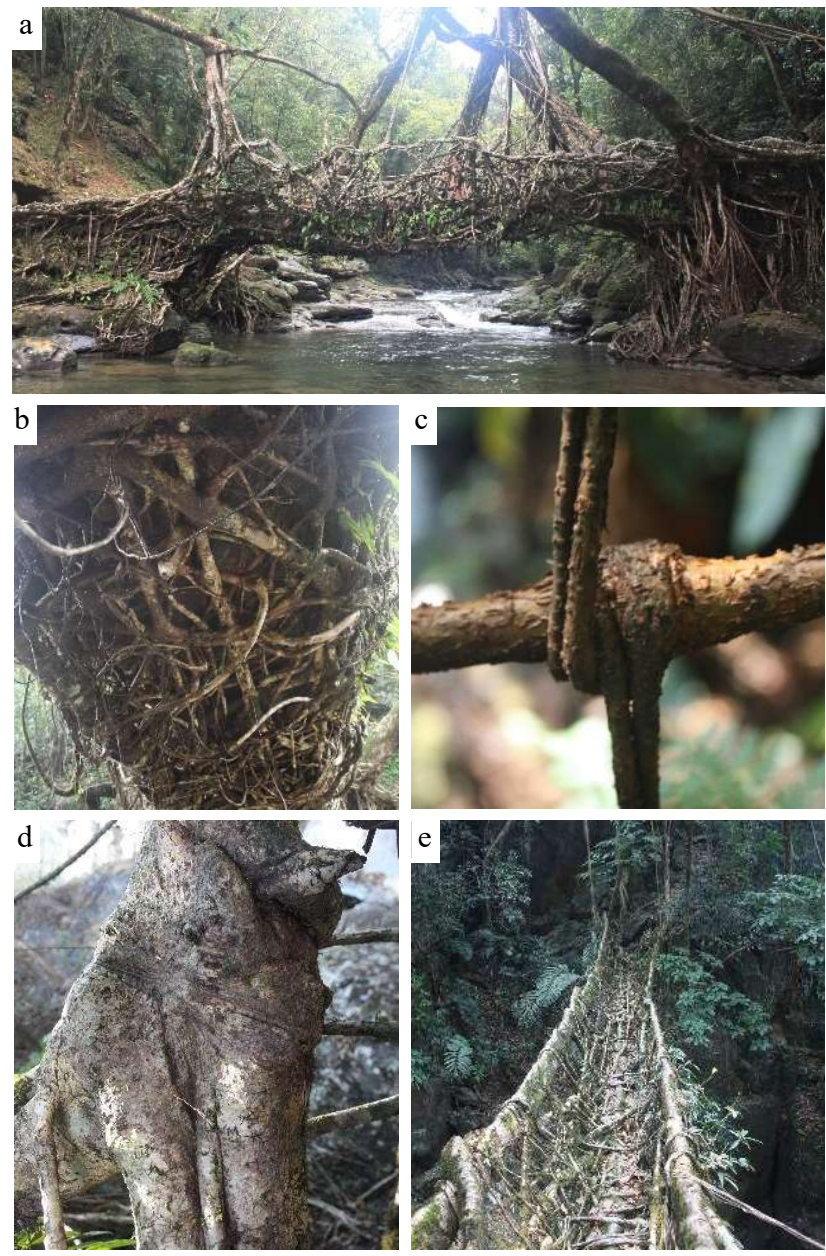

Figure 1: Wah Thyllong bridge (a) is formed of a network of small roots as seen from underneath (b). Roots tied together form inosculated joints, around two years old (c) and much older (d). A small number of long, thick roots are structurally integral to Niah Li bridge (e). 
which increases the chance and rate of inosculation. (Ludwig, 2012) uses technical elements (wires, elastics and screws) to induce this pressure in contemporary living architecture. These aspects appear to influence the structural form of each bridge Figure 1 shows two bridges, Niah Li (Rangthylliang village) and Wah Thyllong (Nohwet village) with very different structural systems. In Niah Li Bridge, a handful of long, thick, elliptical or 'inverted T' shaped roots are grafted into a network by smaller roots. Wah Thyllong bridge is made up of many smaller roots woven together, with no roots of clear importance.

While (Ludwig et al., 2019) use these root and joint characteristics in comparative analysis and evaluation across all bridges, that study does not provide the tools to detail the geometry, topology and structure of a single bridge. A range of structural and physiological analyses of interest to any living architectural project can make use of documentation of a whole bridge, which in turn allow living structural design and maintenance.

\subsection{Analysis of LRBs as living structures}

In mechanical analysis of trees, a variety of mechanical models use trunk/branch thickness to predict structural capacity and growth (James et al., 2006, Mattheck and Bethge, 1998). Contemporary structural analyses (both in classical methods and numerical approximations), make use of a geometric and topological model working in tandem: individual elements of precise geometry are connected by joints which allow stress transmission. Similarly, plant growth models use topology to describe branching positions and geometry to describe branch shapes (Godin et al., 1999). This distinction between elements and joints translates well to LRBs: structurally important roots and inosculated joints are the key functional parts of a bridge.

In addition to whole-bridge analyses, evaluation of individual parts of each bridge are of interest. Moss cover, which can influence nutrient cycling (Nadkarni, 1986), and root/branch decay, which can have structural effects (Mattheck and Breloer, 1994) are seen on LRBs. Visual Tree Analysis (VTA) uses visible signs on the tree's surface to tell the state of health and structure of a trunk, branch or joint (Mattheck, Breloer, 1994). (Ludwig, 2012) discusses the application of similar signs to Baubotanik structures. More widely, where human intervention is a part of a tree's growth (as in inosculated joints in LRBs) a VTA-style assessment should be developed to provide feedback to design and construction methods. For example, assessment of the state of callus growth, as a feature of inosculation (Millner, 1932).

\subsection{Review: photogrammetry for complex structures}

Efforts to document complex structures in both forest science and architecture can inform tools used for living architecture. The precision of close-range terrestrial photogrammetry is well discussed. It is found to be useful in comparison (Grussenmeyer et al., 2008) and in combination (Landes et al., 2007) with TLS and tacheometry. (Liang et al., 2014) finds a handheld consumer camera provides point clouds of similar accuracy to TLS data when applied to a forest stand of approximately $30 \mathrm{~m} \times 30 \mathrm{~m}$. Following automatic stem reconstruction, a less cost-effective multi-camera system is found to have similar accuracy (Forsman et al., 2016).

(Liang et al., 2014) decimate their photogrammetric point clouds by reducing green (foliage) points, helping to isolate stems. Manual decimation is also made easier by colourised points (Landes et al., 2007).
Because structural or other analyses can rely on a range of basic forms (1D thin elements, 2D planes, 3D volumes or shells), the process of topological extraction depends greatly on the expected shape of the structure in question. Methods have been proposed for partially destroyed, thick-walled buildings (Bitelli et al., 2016), arch bridges (Arias et al., 2007) and vertically aligned tree stems (Liang et al., 2012). While these methods are useful for certain structural topologies and provide inspiration for others, methods are often non-transferable as fundamental parts of the process rely on the structure's presumed shape. LRBs' closest topological neighbour may be tubular structures - a wide range of $1 \mathrm{D}$ and 2D skeleton extraction methods are discussed by (Tagliasacchi et al., 2016). The methods discussed there are applied to simple (human form) and complex (blood vessel system) network structures.

\subsection{Requirements for a model describing LRBs}

In vernacular architectures (LRBs) as well as in contemporary living and architectures (e.g. Baubotanik projects, see (Ludwig, 2016 \#635) for a review), growth of new structures, maintenance of old ones, and ensuring safety of use are all valuable outcomes of good models. When considering living architecture, models should have the following four characteristics.

\section{1) Geometric precision}

LRB geometry is complex - roots change shape along their length, inosculations may grow asymmetrically, and the network of interconnected roots can be extensive and diverse. These details can provide structural (Müller et al., 2006, Coutand, 2010) and physiological (Shinozaki et al., 1964) insight, and should be recorded.

2) Colour

A range of analyses are provided by colourised models. Growth of mosses and lichens influence tree and ecosystem health (Nadkarni, 1986), while leafy epiphytes can be easily recognised in a model and deleted accordingly.

3) Topological extraction

In order to extract meaningful structural and physiological information, a topological model should be achievable. The interaction between a geometric and topological model is described by (Godin et al., 1999).

4) Minimal cost

LRBs are generally very inaccessible, usually located in steep terrain and dense forest. The village communities that own, use and maintain the bridges have limited access to educational, financial, and economic resources. The tools used should be of low financial cost, require minimal training, and be portable.

In addition to these characteristics, close-range photogrammetry can provide two services: environmental embedment and changetracking. Environmental factors are crucial to the development of any living structure. The proximity to a river, the slope conditions, surrounding forest, and human systems could each impact a bridge's condition. Previous uses of environmental information include use of a digital terrain model for locating 3D points representing trees (Nurminen et al., 2013).

Previous studies have used close-range photogrammetric surveys to track changes in buildings (Yilmaz et al., 2007) including by algorithmic change detection (Abate, 2019). Aerial photogrammetry is commonly used for change detection in forest science (Muchoney, Haack, 1994), but not close-range photogrammetry. 


\subsection{Scope and aim of this study}

This study presents the first efforts to use photogrammetry to document living structures, in particular the Living Root Bridges, as a case of living architecture. Preliminary point clouds are presented of bridges and details. The usefulness of the technique is discussed with regards to representation and analysis and use in living architecture more widely.

One bridge, Nongriat Access bridge, was surveyed two years running: 2018 and 2019. A layer of soil was added to the path of Nongriat Access bridge to stop tourists' shoes damaging the roots, between the dates of the two surveys. The two surveys were aligned to find whether photogrammetry is an effective tool for logging these changes.

\section{METHODS}

\subsection{Survey methods}

In March 2019, 9 photogrammetric surveys were conducted by the Author 1, following a single preliminary survey (Nongriat Access bridge) in March 2018. They were performed using a Canon EOS 450D digital SLR with a EF-S $18 \mathrm{~mm} \mathrm{f/3.5-5.6} \mathrm{lens.}$ Surveys were conducted in March, near then end of the dry season in Meghalaya. This serves two purposes: the number of leafy epiphytes is reduced, so more root surface is exposed allowing for clearer sight of the bridge topology; and the water level in rivers is low, reducing the problems caused by reflections and allowing greater access to photography sites.

The photographing survey varied between sites. On smaller, more accessible sites, the bridge was photographed in a circular survey, covering as much of a $360^{\circ}$ circle as possible. Steep terrain sometimes prevented access to the full circle. In these instances, more photographs were taken from accessible positions to cover as many angles as possible. Figure $2 \mathrm{a}$ shows the survey taken for Nongriat Access bridge, where the southeast corner is not accessible due to a boulder and river. When photographing larger bridges and their surroundings, the setting was treated as a room (Agisoft, 2018). On all bridges, $20-30 \mathrm{~cm}$ steps were taken in each direction along the deck between photographing positions, at which two or three photos were taken: vertically down onto the deck, at around $30^{\circ}$ and $60^{\circ}$ from the vertical in the direction of travel, as shown in Figure $2 b$. Below each deck the underside was photographed using a survey similar to the deck, though access to the riverbed varied. Where necessary, a flash was used. A spherical survey was attempted for each small joint, as shown in Figure 2c.

\subsection{Point cloud processing}

All models were produced as dense clouds using Agisoft Metashape (version 1.5.1; http://www.agisoft.com, last access: $16^{\text {th }}$ October 2019). Joint sections were constructed from between 58 and 150 photos, whole bridge models between 173 and 1640 photos. CloudCompare was used for manual noise deletion, alignment for comparison between years, and all other point cloud processing required for the results shown (GirardeauMontaut, 2011).

\section{RESULTS}

The first full round of point cloud processing (March 2019) resulted in 9 useful point clouds. Point clouds were also produced for 5 joint details across 3 bridges. Figure 3 shows a range of perspectives from several models. Figure $3 \mathrm{a}-\mathrm{c}$ show Umkar
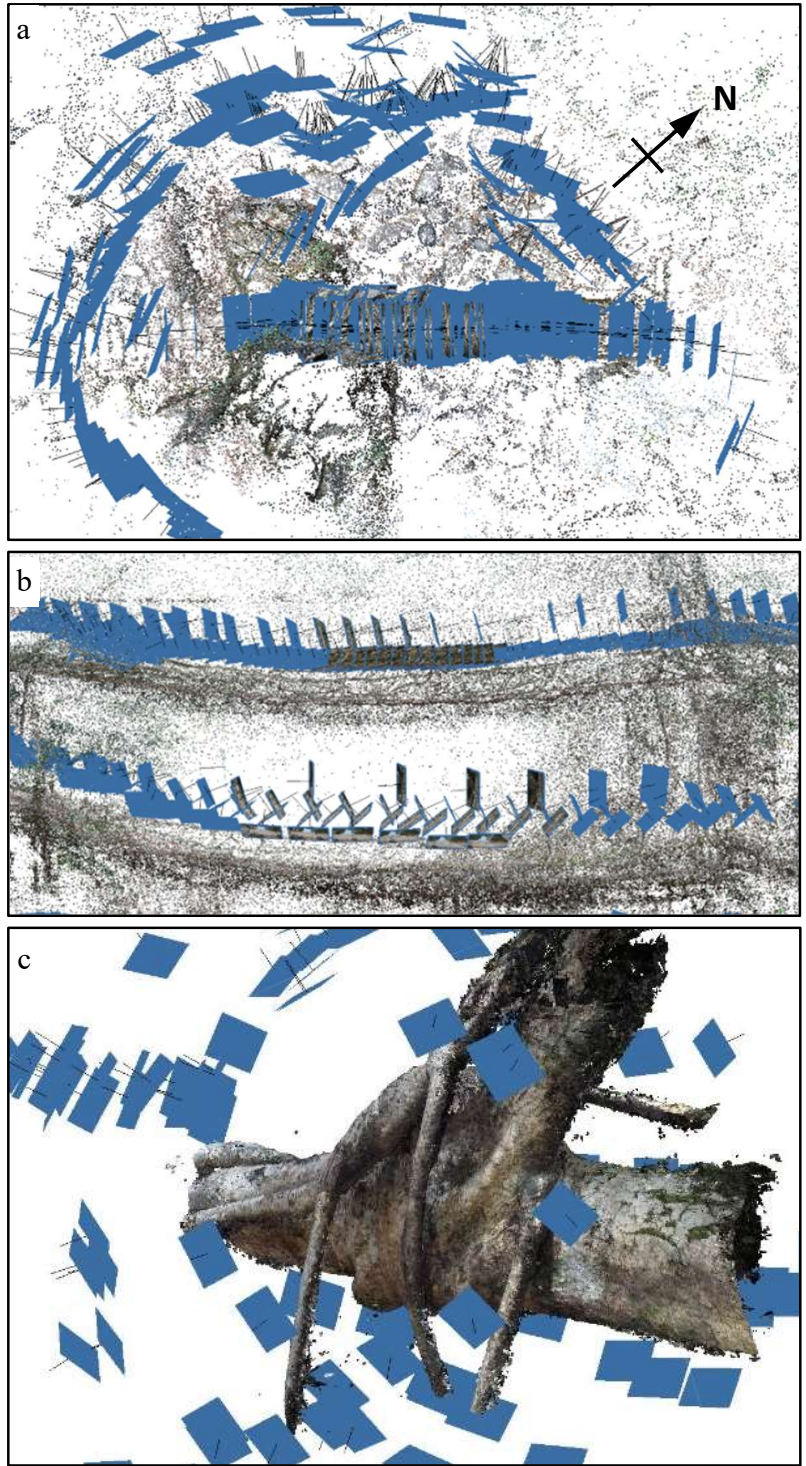

Figure 2: Surveys of LRBs and elements follow basic schema: a $360^{\circ}$ survey of smaller bridges (a, Nongriat Access bridge); regular interval photography of the deck (b, Nongriat

Double Decker) and spherical surveys for joints (c).

bridge at Siej village, which has been addressed in a range of blogs (Allen, 2011), TV documentaries (Flowers, 2011) (Mergner, 2018), and books (Rogers, 2017). Figure 3a shows a section of young roots that have been recently knotted, expected to grow visibly in the coming years, contributing to the stability of the bridge. Figure $3 \mathrm{~b}$ shows the entire bridge from upstream the virtual camera position is behind the hill-face.

Figures 4, 6 and 7 show Nongbareh bridge, which connects two halves of the village of Nongbareh (population ca. 2000). Figures $4 \mathrm{a}$ and $4 \mathrm{c}$ are course photographs that inform the photogrammetric model perspectives in Figures $4 \mathrm{~b}$ and $4 \mathrm{~d}$ ). These show surfaces of the handrails, with three aspects of interest to health assessment. Firstly, callus growth on top of the handrails (i). This may follow a cut in the surface to extract latex (Tynsong et al., 2012) and can cause water pooling, causing rotting of the root. Secondly, moss growth can be seen (ii) which can contribute to the ecosystem nutrient cycle (Sillett et al., 1995). Finally, burned areas of wood are clear to see (Sillett et al.) - either due to sunburn (the bridge is well exposed to the sun 
and not in a forest, unlike most LRBs) or due to fires lit by people. Figure 6 shows the bridge in context, ith the riverbed mapped, which can feed into flood management analysis. Figure $7 \mathrm{~b}$ shows a through-section of the bridge deck and handrails, while Figure 7 a shows the visible roots on the underside of the deck.

Figure 5 shows an inosculated joint in the Mawsaw Hybrid bridge in Nongriat village. This joint is one of several key connections between the bridge and its main supporting tree, and provides water transport functions. Tributary roots are shown - the direction of transport can be understood from a whole-bridge photogrammetric model linking roots to crown. Figure $5 \mathrm{~b}$ shows a callus between two inosculated branches, as described by (Millner, 1932).

The comparison of point clouds resulting from surveys of Nongriat Access bridge between two consecutive years (March 2018 and March 2019) was possible by manual alignment in CloudCompare (Girardeau-Montaut, 2011). Nongriat Access bridge is thought to be 200-250 years old (Ludwig et al., 2019) and the roots in the deck are not expected to have grown significantly within one year. Therefore, reference points are available on the bridge handrails for alignment of the point clouds. Figure 9 shows the aligned clouds and the state of the bridge in 2018 and 2019. A gap stands between the two point clouds, which translates to the compacted soil volume.

\section{DISCUSSION}

Due to the difficult terrain (mainly downstream), the complete planned survey of some bridges (such as Nongriat Access bridge, Figure 2a) could not be completed. Most bridges could be well surveyed from a range of upstream vertical positions. Most of the models, therefore, are significantly more detailed in areas visible from upstream than downstream. In order to even out the survey, drones may be used in conjunction with survey-planning software (Murtiyoso, Grussenmeyer, 2017).

The results of this study show some key benefits for living architecture in photogrammetric documentation. Firstly, 3D digital models can supplement onsite assessments of a whole bridge's condition by comparison of calluses and decay, moss growth and burns across a single bridge (Figures $4 \mathrm{a}-\mathrm{d}$ ). A point cloud can be tagged and manipulated to expose these features as well as placing them in the context of the bridge-tree system. Through such examination, and by building up an archive of contextualised features, a VTA for LRBs could be established (Mattheck, Breloer, 1994). However, cross-examination against the source photographs is still useful (compare Figure $4 \mathrm{a}$ with $4 \mathrm{~b}$, $4 \mathrm{c}$ with $4 d)$.

Secondly, surveys that cover the entire system of roots/shoots from ground to leaf provide the basis for geometric models. As pseudo-cylindrical elements, each root may be represented using a small number of geometric values. Perfectly cylindrical roots require only the central axis (a 1D curve) and associated radii, while elliptical roots require an elliptical ratio and 'inverted-T' shaped roots require a pair of diameters or an asymmetry angle (Ludwig et al., 2019) (Nicoll, Ray, 1996). A range of automated geometry extraction methods have been proposed for cylindrical elements, in particular skeletonisation, from L1-medial point cloud sampling (Huang et al., 2013) to voxel-thinning (She et al., 2009). For structural and physiological (water or nutrient transport) models, an extraction method should preserve topology and minimise data intensity (Godin et al., 1999). However, these methods have generally been shown to work in relatively simple structures (with few joints and evenly sized elements). In a manual root geometry extraction process, comparing figures $7 \mathrm{a}$ and $7 \mathrm{~b}$, the extent of roots in internal spaces can be interpolated. Either a manual or automatic extraction process can be formed that highlights the distinction between element and joint detailed in section 1.1.

Documentation is not only needed for developing topological and geometric models, but also for representation of living architecture. While photogrammetry allows examination of precise models, relevant structural aspects specific to living architecture are not immediately clear. Photographs and basic measurements (Ludwig et al., 2019) allow 2D drawing and 3D physical model-making. The authors have, with student groups, developed models, plans and diagrams that mirror a range of typical architectural representation tools. Figure 10 (top) shows a model of Nongriat Access bridge made from a modelling concrete and wire. Figure 10 shows an aerial plan view and a 'building section' of the bridge deck. These works were presented at the 2019 Sao Paolo Biennale. The structural characteristics discussed in Section 1 are highlighted in these representation techniques. Furthermore, students found that model-building helped them to understand the structural complexity of the woven bridges. A mixture of techniques can provide a range of insights. Baubotanik structures, which have been designed with precise growth (extent, direction and timing) in mind, can benefit greatly from photogrammetric surveys.

(Ludwig, 2012) describes the process of common growth across inosculations, as well as the gradual inclusion of technical connections (screws, elastic or inelastic bands). As the Baubotanik structures are periodically and methodically tended, inosculations could be tracked and growth logged, feeding into the design-maintenance-analysis cycle.

On a whole-structure scale, contemporary Baubotanik projects presents some different challenges to LRBs. The site of the Freiburg Pavilion (Figure 8) is, for example, more accessible than most LRBs, but the Baubotanik structures are generally much taller. More technical elements may cause more occlusion, but the shedding of leaves in the winter may allow better access to the structural elements.

\section{CONCLUSION}

This study presents the first photogrammetric models of Living Root Bridges, discussing the relevant aspects of the models with regards to the bridges' topology, construction and growth. A comparison of two annual point clouds shows the potential for LRBs' many small details as reference points. Where a mix of old and young roots exist, new growth could be well tracked. The development of photogrammetric point clouds into topological models for structural and physiological analyses is discussed. Photogrammetric models are found to make a good contribution to the toolbox being developed for living architecture representation. The method is suggested for extension to living architecture more widely, particularly Baubotanik structures. 


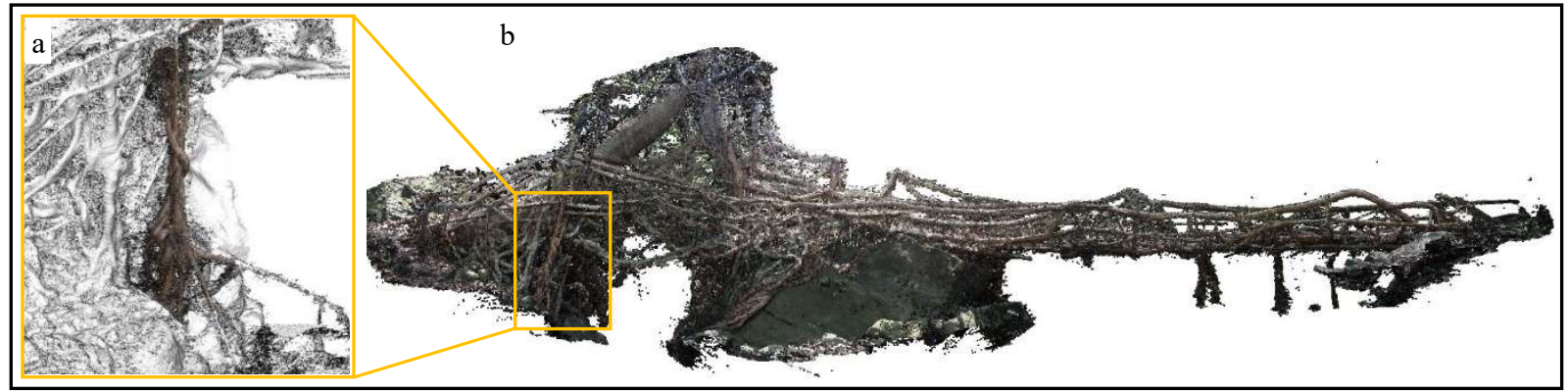

Figure 3: Umkar bridge in Siej village has young roots that are recently knotted (a), expected to grow in the coming years. An upstream perspective, through the hillside slope is achieved with photogrammetric survey (b).
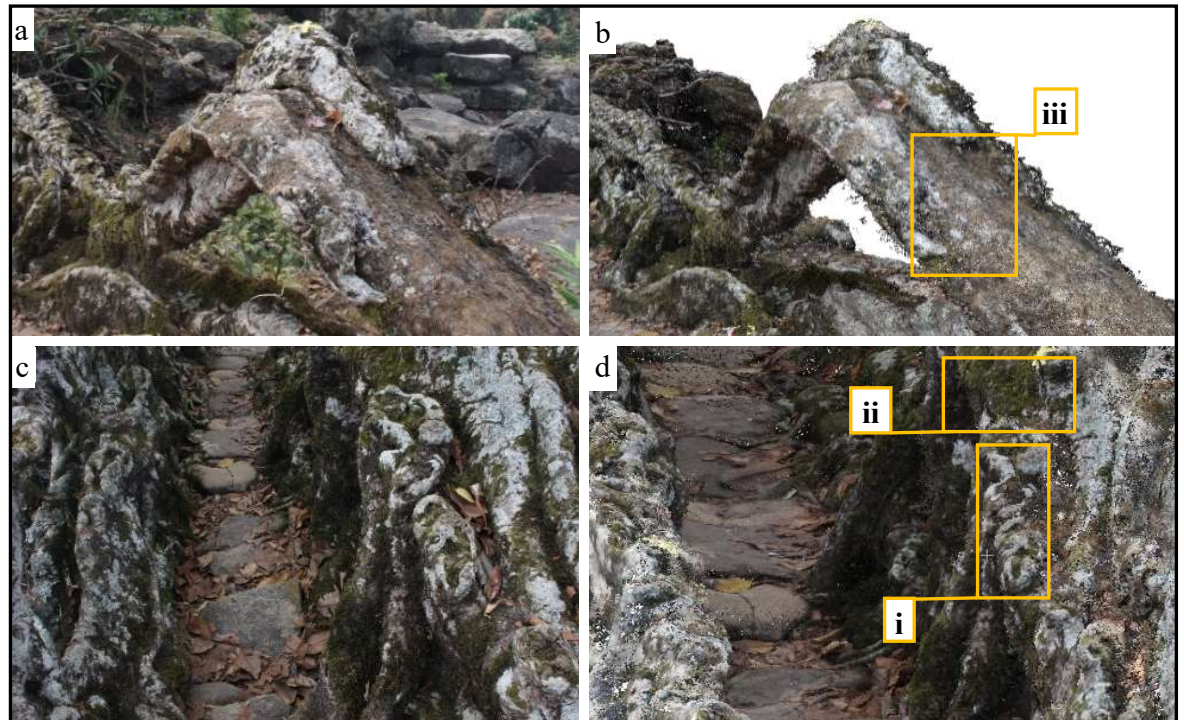

Figure 4: The bridge in the centre of Nongbareh village shows burns on the surface $(a, b)$ and calluses on the top of the handrails, that allow water to pool (c, d). (a) and (c) are photos, (b) and (d) are perspectives of the point cloud.

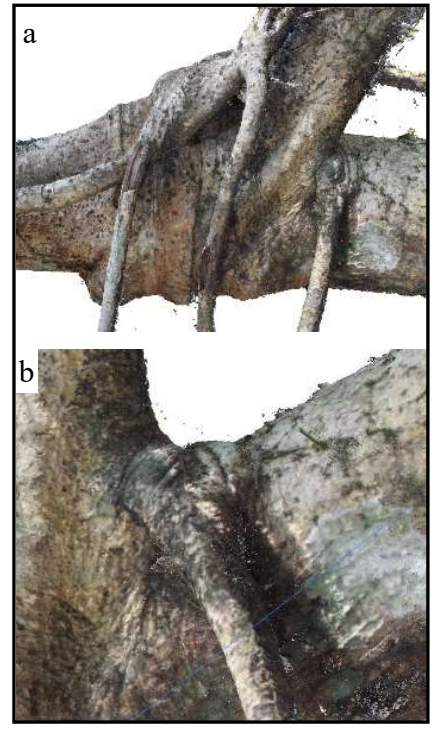

Figure 5: An inosculation provides water transport (a), calluses can be tracked (b)

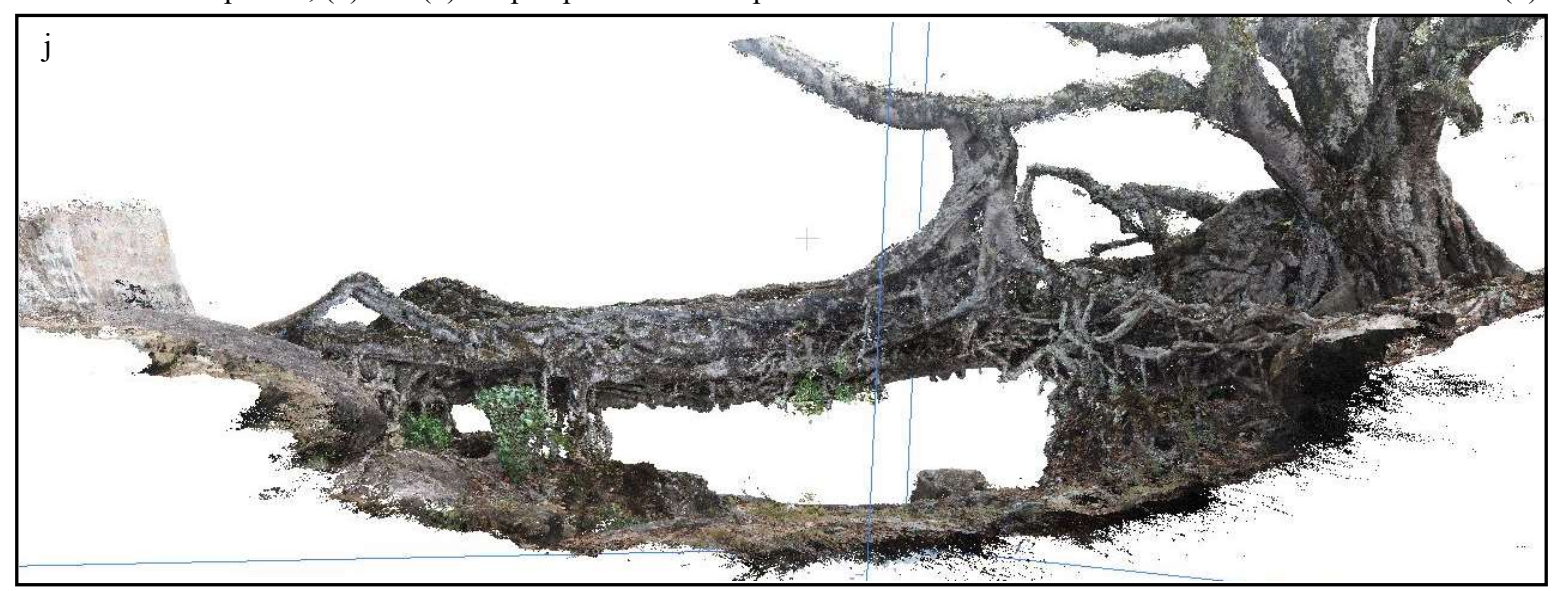

Figure 6: The Amlayeh River under Nongbareh bridge can be mapped in the dry season before floods in July.

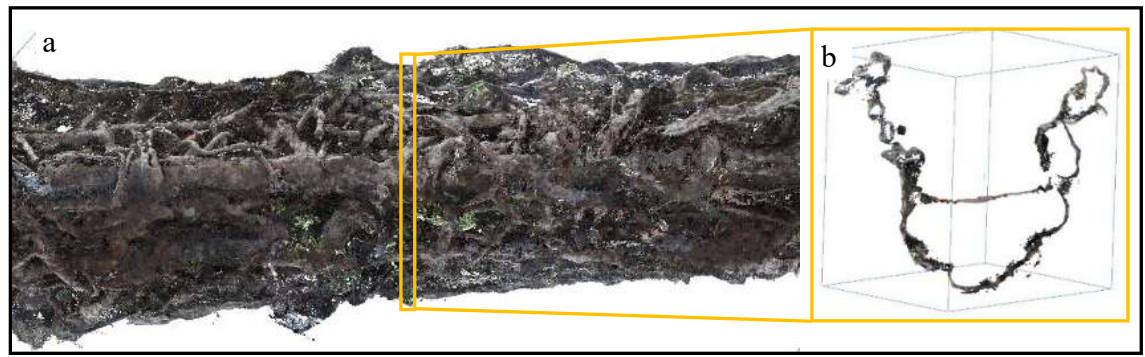

Figure 7: Comparing the underside (a) with through-sections (b) an understanding of the bridge's topology can be gained.

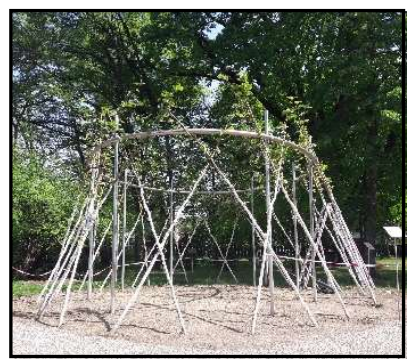

Figure 8: Baubotanik Pavilion Freiburg, photo: Author 3 


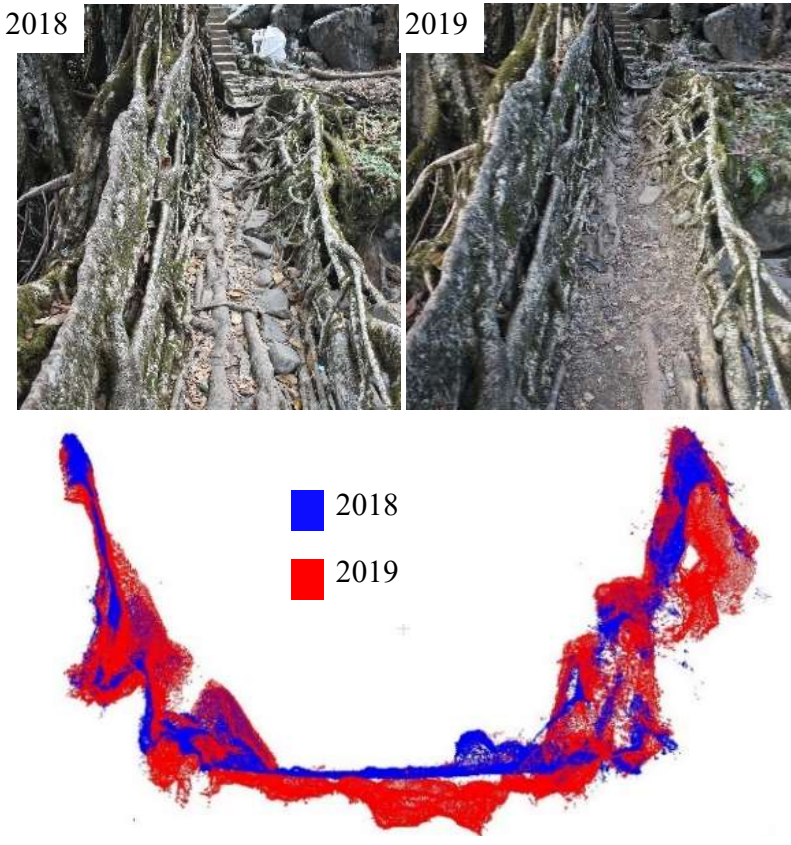

Figure 9: Between March 2018 (left) and March 2019 (right) a layer of soil was added to the deck of the Nongriat Access bridge. Comparing point clouds shows the difference in 3D (bottom).
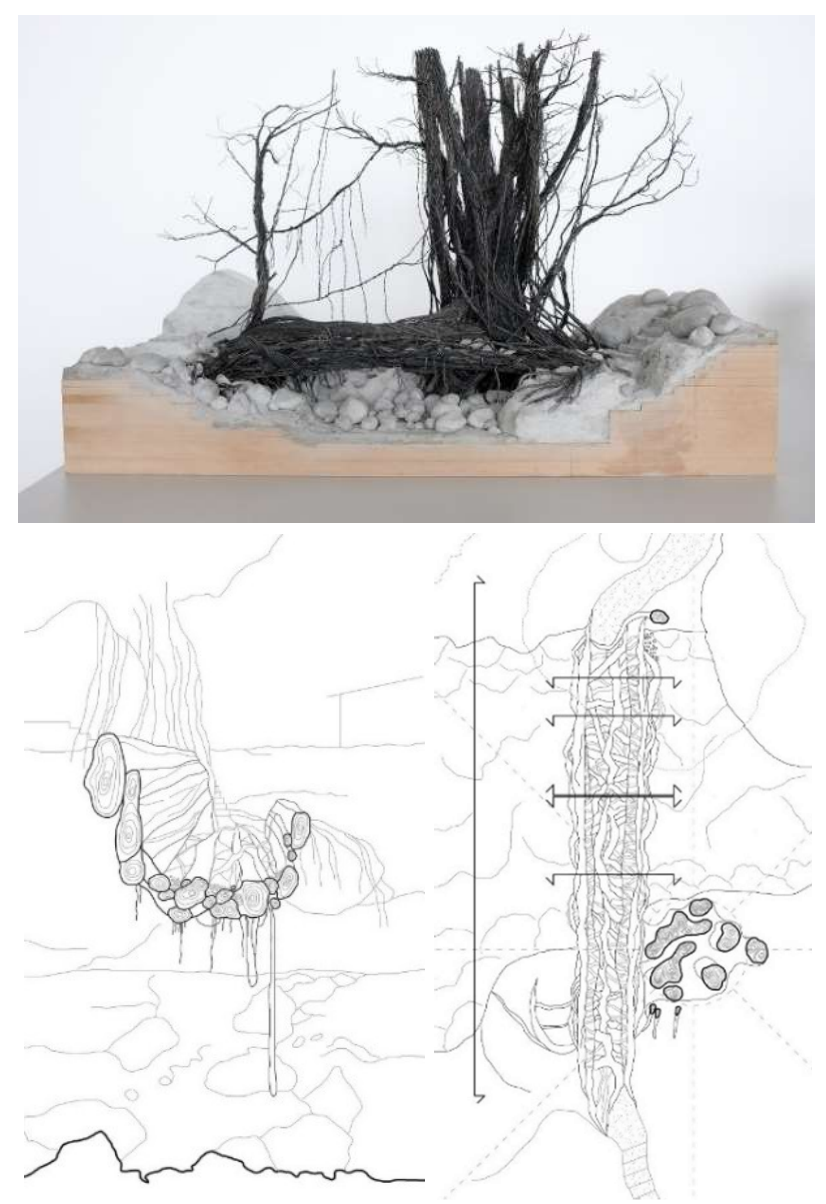

Figure 10: Nongriat Access bridge in modelling concrete and wire (1:25 scale, top), drawn in section diagram (bottom left) and plan (bottom right).

\section{ACKNOWLEDGEMENTS}

The authors are indebted to the Ri War people of Meghalaya and to the Khasi and Jaintia people in general for their great innovation in living architecture (Jingkieng Jri), and their forest management practices which can inspire regenerative attitudes around the world. Generations of Khasi and Jaintia people have contributed to the formation of this architecture, and their descendants are the rightful owners of the fruits of this labour. In particular, we thank the people of Siej, Rangthylliang, Mawkyrnot, Shnongpdeng, Nongbareh, Kudeng Rim \& Thymmai, Nongriat, Myntheng, Nongthymmai, Nohwet, Riwai and Mawlynnong, Nongblai, Burma, Padu and Shuthim for their work in growing and conserving the bridges and forests, and for their hospitality during our stays with them. The authors thank the students of Green Technologies in Landscape Architecture 2018 for their contributions to diagrams and models of LRBs.

\section{REFERENCES}

Allen, T. 2011: Living Root Bridges. Human Planet. Available at: http://humanplanet.com/timothyallen/2011/03/living-rootbridges-bbc-human-planet/ (Accessed 30 July 2019)

Abasolo, W., Yoshida, M., Yamamoto, H. \& Okuyama, T. 2009: Stress generation in aerial roots of Ficus elastica (Moraceae). IAWA Journal, 30(2), 216-224.

Abate, D. 2019: Built-heritage multi-temporal monitoring through photogrammetry and $2 \mathrm{D} / 3 \mathrm{D}$ change detection algorithms. Studies in Conservation, 64(7), 423-434.

Agisoft, 2018: Agisoft metashape user manual, Professional edition, Version 1.5. Agisoft LLC, St. Petersburg, Russia, from https://www. agisoft. com/pdf/metashape-pro_1_5_en. pdf, (Accessed 2 June 2019)

Arias, P., Armesto, J., Di-Capua, D., González-Drigo, R., Lorenzo, H. \& Perez-Gracia, V. 2007: Digital photogrammetry, GPR and computational analysis of structural damages in a mediaeval bridge. Engineering Failure Analysis, 14(8), 14441457.

Bitelli, G., Castellazzi, G., D'Altri, A., De Miranda, S., Lambertini, A. \& Selvaggi, I. 2016: Automated voxel model from point clouds for structural analysis of cultural heritage. International Archives of the Photogrammetry, Remote Sensing \& Spatial Information Sciences, 41.

Coutand, C. 2010: Mechanosensing and thigmomorphogenesis, a physiological and biomechanical point of view. Plant Science, 179(3), 168-182.

BBC, 2011: Rivers: friend or foe. Human Planet Directed by Flowers, M., Brown N., Jones, T.H., Stone, T.

Forsman, M., Börlin, N. \& Holmgren, J. 2016: Estimation of Tree Stem Attributes Using Terrestrial Photogrammetry with a Camera Rig. Forests, 7(3), 61.

Girardeau-Montaut, D. 2011: Cloudcompare - Open Source Project. http://cloudcompare.org/ (Accessed 20 October 2019) 
Godin, C., Costes, E. \& Sinoquet, H. 1999: A method for describing plant architecture which integrates topology and geometry. Annals of botany, 84(3), 343-357.

Grussenmeyer, P., Landes, T., Voegtle, T. \& Ringle, K. 2008: Comparison methods of terrestrial laser scanning, photogrammetry and tacheometry data for recording of cultural heritage buildings. International Archives of Photogrammetry, Remote Sensing and Spatial Information Sciences, 37(B5), 213218.

Huang, H., Wu, S., Cohen-Or, D., Gong, M., Zhang, H., Li, G. \& Chen, B. 2013: L1-medial skeleton of point cloud. ACM Trans. Graph., 32(4), 65:1-65:8.

James, K., Haritos, N. \& Ades, P. 2006: Mechanical stability of trees under dynamic loads. American Journal of Botany, 93(10), $1522-1530$.

Jim, C. 2014: Ecology and conservation of strangler figs in urban wall habitats. Urban ecosystems, 17(2), 405-426.

Landes, T., Grussenmeyer, P., Voegtle, T. \& Ringle, K. Combination of Terrestrial Recording Techniques for 3D Object Modelling regarding topographic constraints. Example of the Castle of Haut-Andlau, Alsace, France. XXIth CIPA International Symposium, 2007. 435-440.

Liang, X., Hyyppä, J., Kaartinen, H., Holopainen, M., Melkas, T. 2012: Detecting changes in forest structure over time with bitemporal terrestrial laser scanning data. ISPRS International Journal of Geo-Information, 1(3), 242-255.

Liang, X., Jaakkola, A., Wang, Y., Hyyppä, J., Honkavaara, E., Liu, J. \& Kaartinen, H. 2014: The use of a hand-held camera for individual tree $3 \mathrm{D}$ mapping in forest sample plots. Remote Sensing, 6(7), 6587-6603.

Ludwig, F. 2012: Botanische Grundlagen der Baubotanik und deren Anwendung im Entwurf. Stuttgart.

Ludwig, F., 2016: Materiality and Architecture. Routledge, London.

Ludwig, F., Middleton, W., Gallenmüller, F., Rogers, P. \& Speck, T. 2019: Living bridges using aerial roots of ficus elastica-an interdisciplinary perspective. Scientific reports, 9 (1), $1-11$.

Mattheck, C. \& Bethge, K. 1998: The Structural Optimization of Trees. Naturwissenschaften, 85(1), 1-10.

Mattheck, C. \& Breloer, H. 1994: Field guide for visual tree assessment (VTA). Arboricultural Journal, 18(1), 1-23.

Arte, 2018: Baubotanik - Die Natur als Baumeister, Xenius. Directed by Mergner, G.

Millner, E. M. 1932: Natural grafting in hedera helix. The new phytologist, 31(1), 2-25.

Muchoney, D. M. \& Haack, B. N. 1994: Change detection for monitoring forest defoliation. Photogrammetric engineering and remote sensing, 60(10), 1243-1252.

Müller, U., Gindl, W. \& Jeronimidis, G. 2006: Biomechanics of a branch-stem junction in softwood. Trees, 20(5), 643-648.
Murtiyoso, A. \& Grussenmeyer, P. 2017: Documentation of heritage buildings using close-range UAV images: dense matching issues, comparison and case studies. The Photogrammetric Record, 32(159), 206-229.

Nadkarni, N. M. 1986: The nutritional effects of epiphytes on host trees with special reference to alteration of precipitation chemistry. Selbyana, 44-51.

Nicoll, B. C. \& Ray, D. 1996: Adaptive growth of tree root systems in response to wind action and site conditions. Tree physiology, 16(11-12), 891-898.

Nurminen, K., Karjalainen, M., Yu, X., Hyyppä, J., Honkavaara, E. 2013: Performance of dense digital surface models based on image matching in the estimation of plot-level forest variables. ISPRS Journal of Photogrammetry and Remote Sensing, 83, 104115.

Rogers, P. 2017: The Green Unknown: Travels in the Khasi Hills. Amazon: Westland.

Shankar, S. 2015: Living Root Bridges: State of knowledge, fundamental research and future application. IABSE Symposium Report: Structural Engineering: Providing Solutions to Global Challenges, 1, 1974-1981.

She, F., Chen, R., Gao, W., Hodgson, P., Kong, L., Hong, H., 2009: Improved 3D thinning algorithms for skeleton extraction. Digital Image Computing: Techniques and Applications, IEEE, 14-18.

Shinozaki, K., Yoda, K., Hozumi, K. \& Kira, T., 1964: A quantitative Analysis of Plant Form - The Pipe Model Theory : I. Basic Analyses. Japanese Journal of Ecology, 14(3), 97-105.

Sillett, S. C., Gradstein, S. R. \& Griffin III, D. 1995: Bryophyte diversity of Ficus tree crowns from cloud forest and pasture in Costa Rica. Bryologist, 251-260.

Tagliasacchi, A., Delame, T., Spagnuolo, M., Amenta, N. \& Telea, A. 2016: 3d skeletons: A state-of-the-art report. Computer Graphics Forum, 35(2), 573-597.

Tynsong, H., Tiwari, B. \& Dkhar, M. 2012: Bird hunting techniques practised by War Khasi community of Meghalaya, North-east, India. Indian Journal of Traditional Knowledge 11(2), 334-341

Yilmaz, H. M., Yakar, M., Gulec, S. A. \& Dulgerler, O. N. 2007: Importance of digital close-range photogrammetry in documentation of cultural heritage. Journal of Cultural Heritage, $8(4), 428-433$.

Zimmermann, M. H., Wardrop, A. B. \& Tomlinson, P. B. 1968. Tension Wood in Aerial Roots of Ficus Benjamina L. Wood Science and Technology, 2(2), 95-104. 